\title{
Digestibilidade e parâmetros ruminais de dietas à base de forragem com adição de própolis e monensina sódica para bovinos ${ }^{1}$
}

\section{Odimári Pricila Pires do Prado², 4, Lucia Maria Zeoula3, 4, Lucimar Pontara Peres de Moura3, Selma Lucy Franco ${ }^{5}$, Ivanor Nunes do Prado ${ }^{3}, 4$, Hanna Carla Cardoso Gomes ${ }^{6}$}

1 Pesquisa financiada pelo CNPq e pela Fundação Araucária.

2 Doutoranda em Zootecnia - UEM.

${ }^{3}$ Departamento de Zootecnia - UEM.

${ }^{4}$ Bolsista do CNPq.

${ }^{5}$ Departamento de Farmácia - UEM

${ }^{6}$ Graduanda em Zootecnia - Bolsista IC/CNPq - UEM.

RESUMO - Avaliaram-se os efeitos da utilização de produtos contendo própolis em duas concentrações (B e C) e duas extrações alcoólicas (1 e 3) e de monensina sódica em dieta à base de forragem sobre o consumo, a digestibilidade total e parcial e as características ruminais em bovinos. Utilizaram-se quatro bovinos da raça Holandesa, castrados, com peso corporal de $221 \pm 21 \mathrm{~kg}$, canulados no rúmen, em delineamento experimental quadrado latino $4 \times 4$. As dietas experimentais foram constituídas de $72,5 \%$ de volumoso e 27,5\% de concentrado e apresentaram 14,4\% de PB e 67\% de nutrientes digestíveis totais (NDT), diferindo apenas quanto à presença de aditivos. Os consumos médios de matéria seca e nutrientes, não foram afetados pelas dietas, exceto o de NDT, que foi maior nos animais alimentados com a dieta controle. O fornecimento dos aditivos, principalmente própolis, reduziu a digestibilidade total de matéria seca, proteína bruta e NDT. A digestibilidade total da fibra em detergente neutro (FDN) foi semelhante entre aditivos e menor que nos animais controle. A inclusão de própolis refletiu em menor pH ruminal e maiores produções de acetato e AGV totais e a monensina propiciou a menor razão acetato:propionato. A adição dos aditivos avaliados tem efeito negativo sobre a concentração e consumo de energia digestível de dietas à base de forragem fornecida para bovinos em crescimento.

Palavras-chave: ácidos graxos voláteis, digestibilidade parcial, nitrogênio amoniacal, pH ruminal, taxa de diluição

\section{Digestibility and ruminal parameters of diet based on forage with the addition of propolis and sodium monensin for steers}

\begin{abstract}
It was evaluated the effects of using products containing propolis in two propolis concentrations (B and C) and two alcoholic extractions (1 and 3) and sodium monensin in forage based diet on intake, total and partial digestibility and ruminal characteristics in cattle. It was used four Holstein castrated bovines, with body weight of $221 \pm 21 \mathrm{~kg}$, implanted with ruminal cannulla, in a $4 \times 4$ Latin square experimental design. The experimental diets were composed of $72.5 \%$ roughage and $27.5 \%$ concentrate and had $14.4 \%$ crude protein and $67 \%$ of total digestible nutrients (TDN), only differing to the presence of additives. The average intake of dry matter and nutrients did not differ among diets, except for the intake of TDN that was higher for animal fed control diet. The supply of additives, mainly propolis, reduced the total digestibility of dry matter (DM), crude protein (CP) and total digestible nutrients (TDN). The total digestibility of neutral detergent fiber was similar among additives and it was lower than the control animals. The inclusion of propolis reflected in lower $\mathrm{pH}$ and production of acetate and total volatile fatty acids and monensin resulted in lower acetate:propionate ratio. The addition of the evaluated additives has negative effect on the concentration and intake of digestible energy of roughage based diets for growing cattle.
\end{abstract}

Key Words: ammonia nitrogen, partial digestibility, rate of dilution, ruminal $\mathrm{pH}$, volatile fatty acids

\section{Introdução}

O rebanho bovino brasileiro é constituído de 159 milhões de animais, $88 \%$ terminados em pastejo (Anualpec, 2007). A monensina sódica tem sido testada com a finalidade de diminuir perdas de energia e melhorar o ganho de peso. Segundo Goodrich et al. (1984), bovinos em pastagem sob suplementação com monensina ganham $13,5 \%$ mais peso que aqueles em pastagem exclusiva. Além disso, bovinos a pasto recebendo monensina aumentam o ganho de peso diário e a eficiência alimentar (Nagajara et al., 1997). 
Todavia, o uso de ionóforos está proibido na União Europeia desde $1^{\circ}$ de janeiro de 2006 (Regulamento CE, 2003). Assim, a própolis tem sido estudada como alternativa natural aos ionóforos na alimentação de ruminantes, pois possui inúmeras substâncias ativas em sua composição, destacando-se os flavonoides, que apresentam ação bacteriostática e bactericida, principalmente contra bactérias Gram-positivas (Antunes et al., 1996).

Em estudos sobre a microbiota ruminal, Broudiscou et al. (2000) testaram a própolis e observaram aumento de 10\% na produção de propionato em 10,3\% e redução da população de protozoários. A própolis também foi eficiente em diminuir a produção de amônia de fontes de nitrogênio, tanto in vitro como in vivo (Stradiotti Jr. et al., 2004; Oliveira et al., 2006).

Na avaliação de produtos contendo extrato de própolis, LLOS (PI = nº605768-3) em diferentes concentrações de própolis (A, B, C e D) e extrações alcoólicas (1, 2 e 3) foram registrados resultados positivos quando adicionados na ração de ruminantes. Prado (2005) observou aumento de $25,5 \%$ na digestibilidade in vitro da matéria seca (DIVMS) de rações com $100 \%$ de volumoso quando utilizou o produto LLOSB3 e de 8,3\% quando forneceu o produto LLOSC1 em comparação à monensina sódica. Casimiro (2008) não notou efeito da substituição de lasalocida sódica por produtos contendo própolis (LLOSC1 e LLOSA2) sobre o desempenho, a conversão alimentar e a digestibilidade das rações em bezerras holandesas lactentes alimentadas do nascimento ao desmame (60 dias) com leite e concentrado.

Para características de carcaça, de ovinos terminados em confinamento, não foi verificado efeito da adição de própolis verde e marrom quando adicionadas à ração (Ítavo et al. 2009).

Assim, objetivou-se estudar os produtos LLOSB3 e LLOSC1 em duas concentrações de própolis (B e C) e duas extrações alcoólicas (1 e 3) e monensina sódica em dietas à base de forragem e avaliar os efeitos desses produtos no consumo, na digestibilidade total e parcial e nas características ruminais em bovinos.

\section{Material e Métodos}

O experimento foi realizadosetor de Bovinocultura de Corte da Fazenda Experimental de Iguatemi, no Laboratório de Alimentação e Nutrição Animal e no Laboratório de Farmacotécnica pertencentes a Universidade Estadual de Maringá (UEM).

Foram utilizados quatro bovinos, castrados, com peso corporal inicial de $221 \pm 21 \mathrm{~kg}$. Os animais foram fistulados no rúmen e mantidos em baias individuais cobertas, com piso de concreto, providas de comedouro e bebedouro e alimentados com dietas com razão volumoso:concentrado de 72,5: 27,5\%, formuladas para conter $14 \%$ de PB e $67 \%$ de NDT (Tabela 1), e diferentes apenas quanto à inclusão de aditivo: monensina sódica, LLOSC1; LLOSB3; e controle (sem aditivo).

Os produtos contendo própolis (LLOSC1 e LLOSB3) em pó foram preparados de acordo com metodologia desenvolvida por Franco \& Bueno (1999) em duas concentrações de própolis (B e C) e duas extrações alcoólicas (1 e 3). Para os produtos LLOS foi solicitada a concessão de patente ao Instituto Nacional da Propriedade Industrial (INPI), cujo número do Depósito Nacional de Pedido de Patente foi PI 0605768-3. Os teores de flavonóides totais em crisina, quantificados em cromatografia de alta eficiência (HPLC) por Prado (2005) foram de 0,018 $\mathrm{mg} / \mathrm{g}$ de produto LLOSC1 e de $0,0011 \mathrm{mg} / \mathrm{g}$ de produto LLOSB3. Esses produtos foram selecionados a partir de estudos in vitro realizados anteriormente e promoveram maior DIVMS de rações com 100\% de feno de tifton (Prado, 2005).

Tabela 1 - Composição dos ingredientes da ração experimental

\begin{tabular}{|c|c|c|c|c|c|c|c|c|}
\hline \multirow[b]{2}{*}{$\begin{array}{l}\text { Componente } \\
\text { (\% na MS) }\end{array}$} & \multicolumn{7}{|c|}{ Ingrediente } & \multirow[b]{2}{*}{$\begin{array}{c}\text { Ração completa } \\
(72,5: 27,5)^{2}\end{array}$} \\
\hline & $\begin{array}{l}\text { Silagem de } \\
\text { milho }\end{array}$ & $\begin{array}{c}\text { Feno de } \\
\text { capim-tifton }\end{array}$ & $\begin{array}{l}\text { Farelo } \\
\text { de soja }\end{array}$ & $\begin{array}{l}\text { Milho } \\
\text { moído }\end{array}$ & Uréia & $\begin{array}{c}\text { Óleo } \\
\text { de soja }\end{array}$ & $\begin{array}{c}\text { Sal } \\
\text { mineral }^{1}\end{array}$ & \\
\hline Matéria seca (\%) & 34,47 & 93,97 & 91,68 & 90,65 & 99,00 & 99,00 & 99,00 & 60,49 \\
\hline Matéria orgânica & 95,17 & 95,41 & 93,57 & 98,78 & - & - & - & 93,23 \\
\hline Proteína bruta & 7,48 & 5,17 & 50,37 & 8,83 & 312,12 & - & - & 14,38 \\
\hline Extrato etéreo & 2,38 & 0,77 & 2,09 & 3,09 & - & 99,90 & - & 2,62 \\
\hline Fibra em detergente neutro & 60,19 & 82,79 & 10,66 & 15,42 & - & - & - & 50,93 \\
\hline Fibra em detergente ácido & 36,66 & 42,22 & 10,33 & 4,03 & - & - & - & 29,16 \\
\hline Carboidratos totais & 85,31 & 89,47 & 41,11 & 86,87 & - & - & - & 79,85 \\
\hline Carboidratos não-fibrosos & 25,12 & 6,69 & 30,45 & 71,45 & - & - & - & 28,92 \\
\hline$\%$ na dieta & 55,25 & 17,25 & 9,70 & 15,30 & 1,00 & 0,50 & 1,00 & 100,00 \\
\hline
\end{tabular}

${ }^{1}$ Composição por quilo de sal mineral: P - 65,0 g; Ca - 130,0 g; Mg - 5,0 g; S - 13,0 g; Fe - 700 mg; Cu - 850 mg; Mn - 1.000 mg; I - 120 mg; Co - 80 mg.

${ }^{2}$ Relação volumoso:concentrado. 
Para o fornecimento de monensina sódica, foi utilizado o produto comercial Rumensin ${ }^{\circledR}$, que contém $10 \%$ do princípio ativo e dose recomendada pelo fabricante, de $2 \mathrm{~g}$ do produto/animal/dia. As doses dos produtos contendo própolis (LLOS) foram calculadas de maneira que as concentrações avaliadas estivessem contidas também em $2 \mathrm{~g}$ de produto LLOS/animal/dia.

Todos os aditivos foram pesados em separado, embalados em papel higroscópico contendo $1 \mathrm{~g}$ do aditivo. Os aditivos foram colocados diretamente no rúmen do animal via cânula ruminal, no momento da alimentação matutina (8 h) e da vespertina (16 h) assegurando o fornecimento da dose diária de $2 \mathrm{~g}$ de aditivo.

Cada período experimental foi de 21 dias (ao todo quatro períodos): 14 dias para adaptação dos animais às dietas e 7 dias de coleta. Do primeiro ao quarto dia do período de coleta, foram amostrados cerca de $400 \mathrm{~mL}$ de digesta omasal/dia, obtida por sucção do conteúdo omasal por meio do orifício retículo-omasal, segundo técnica descrita por Leão et al. (2005). A coleta foi realizada, no primeiro dia, às $8 \mathrm{~h}$, no segundo dia às $12 \mathrm{~h}$, no terceiro dia às $16 \mathrm{~h}$ e no quarto dia às $20 \mathrm{~h}$, perfazendo um total de quatro amostras por animal em cada período. Os dois últimos dias de coleta foram utilizados para a coleta de líquido ruminal e conteúdo ruminal para avaliação das características da fermentação. Os animais foram pesados no final de cada período de adaptação e de coleta para estimar o consumo de matéria seca e de nutrientes em relação ao peso corporal dos animais.

Para determinação do $\mathrm{pH}$, do nitrogênio amoniacal $\left(\mathrm{N}-\mathrm{NH}_{3}\right)$ e dos ácidos graxos voláteis, foi coletado o fluido ruminal no quinto dia do período de coleta, via cânula ruminal, nos tempos zero (0), 2, 4, 6 e 8 horas após a alimentação matutina. $\mathrm{O} \mathrm{pH}$ foi determinado imediatamente após a coleta. Aproximadamente $50 \mathrm{~mL}$ foram acidificados com $1 \mathrm{~mL}$ de ácido sulfúrico 1:1 para posterior determinação das concentrações de $\mathrm{N}-\mathrm{NH}_{3}$ e de ácidos graxos voláteis. Para a análise de ácidos graxos voláteis, foi adquirida coluna cromatográfica específica que suporta valores de pH baixos e aplicada a metodologia descrita por Bock et al. (1991). A dosagem de amônia nas amostras de líquido ruminal foi realizada pela técnica de Ferner (1965) modificada por Vieira (1980).

Foram administrados no rúmen dos animais $30 \mathrm{~g}$ de Co-EDTA diluídos em $500 \mathrm{~mL}$ de água destilada antes da primeira alimentação e infundidos em dose única para a determinação da taxa de passagem de líquidos (Uden et al., 1980). Foram coletados cerca de $50 \mathrm{~mL}$ de líquido ruminal antes da infusão e a cada 2 horas até completar 12 horas, e uma última coleta às 24 horas após a administração do marcador.

Durante o período experimental, foram feitas pesagens diárias do alimento fornecido e das sobras, que foram amostradas e armazenadas. Todas as amostras de líquido e conteúdo ruminal foram armazenadas separadamente em embalagens plásticas específicas, previamente etiquetadas e congeladas a $-20^{\circ} \mathrm{C}$ para análises químicas posteriores.

Para determinação dos fluxos diários de matéria seca no rúmen, intestino e nas fezes, foi utilizado o óxido crômico $\left(\mathrm{Cr}_{2} \mathrm{O}_{3}\right)$ como indicador externo. Diariamente, às 8 e $16 \mathrm{~h}$, foram fornecidas duas doses intrarruminais diariamente (8 e 16 h) de 5 g de óxido crômico, previamente, pesado e acondicionado em papel higroscópico, perfazendo um total de $10 \mathrm{~g}$ de $\mathrm{Cr}_{2} \mathrm{O}_{3} /$ dia. As concentrações de óxido de cromo nas amostras de digesta omasal e fezes foram determinadas por meio de espectrofotômetro de absorção atômica, após digestão nitroperclórica (Kimura \& Miller, 1957).

Os teores de matéria seca, matéria orgânica, proteína bruta e extrato etéreo foram determinados segundo metodologias descritas por Silva \& Queiroz (2002). As determinações de fibra em detergente neutro (FDN) e fibra em detergente ácido (FDA) foram conduzidas de acordo com Van Soest et al. (1991).

Para quantificação dos carboidratos totais (CHT) e não-estruturais (CNE), utilizaram-se as equações descritas por Sniffen et al. (1992): $\mathrm{CHT}=100-(\% \mathrm{~PB}+\% \mathrm{EE}+\%$ Cinzas $)$ e $\mathrm{CNE} \%=100-(\% \mathrm{~PB}+\% \mathrm{FDN}+\% \mathrm{EE}+\%$ Cinzas $)$. Os valores de NDT observados para cada dieta foram calculados para as diferentes dietas pela equação: NDT $=$ PBD + EED*2,25 + CHTD, em que PBD = proteína bruta digestível, EED = extrato etéreo digestível e CHTD = carboidratos totais digestíveis.

Os coeficientes de digestibilidade totais e parciais da matéria seca e demais nutrientes foram calculados de acordo com as fórmulas descritas por Coelho da Silva \& Leão(1979).

A taxa de passagem de líquido e as curvas de concentração ruminal do cobalto EDTA foram ajustadas ao modelo exponencial unicompartimental de Hungate (1966), citado por Colucci (1984): $\mathrm{Y}_{\text {cobalto }}=\mathrm{A} \times \mathrm{e}^{\left(-\mathrm{k}_{\mathrm{l}} \mathrm{t}\right)}$, em que $\mathrm{Y}_{\text {cobalto }}=$ concentração do indicador no tempo $\mathrm{t} ; \mathrm{A}=$ concentração de equilíbrio do cobalto; $\mathrm{kl}=$ taxa de passagem ou de diluição do cobalto; e $\mathrm{t}=$ tempo de amostragem.

Os parâmetros da dinâmica da fase líquida foram calculados de acordo com Colucci et al. (1990): tempo de retenção no rúmen $(\mathrm{h})=1 /$ taxa de passagem de fluidos $(\% / h)$; volume de líquido ruminal $(\mathrm{L})=$ quantidade de cobalto fornecida $(\mathrm{mg}) / \mathrm{A}$; taxa de fluxo ruminal $(\mathrm{L} / \mathrm{h})=$ 
$\mathrm{k}_{\mathrm{lCo}} \times \mathrm{VLR}$; taxa de reciclagem da fase líquida ruminal $\left(\mathrm{n}^{\circ}\right.$ de vezes/dia $)=24 \mathrm{~h} /$ TeR calculada conforme Maeng \& Baldwin (1976).

Os dados foram analisados em delineamento quadrado latino $4 \times 4$, com quatro animais, quatro períodos. As análises estatísticas das variáveis estudadas foram interpretadas no SAS (Sistema de Análises Estatísticas, versão 9.1) por meio de análise de variância no procedimento PROC GLM.

Para os valores de $\mathrm{pH}, \mathrm{N}-\mathrm{NH}_{3}$ e ácidos graxos voláteis no líquido ruminal, procederam-se à subdivisão de parcelas experimentais de acordo com os tempos de amostragem. Foi utilizada a análise de regressão para as concentrações de $\mathrm{pH}, \mathrm{N}-\mathrm{NH}_{3}$ e ácidos graxos voláteis do líquido ruminal em cada tempo após a alimentação da manhã (zero, 2, 4, 6, 8 horas) para cada dieta e o efeito de hora foi desdobrado em polinômio ortogonal. As diferenças entre as médias das dietas foram determinadas pelo teste Tukey considerando 5\% o grau de significância e até $10 \%$ de probabilidade como tendência.

\section{Resultados e Discussão}

Não houve efeito da inclusão de própolis e monensina sódica $(\mathrm{P}>0,05)$ sobre os consumos de matéria seca e demais nutrientes, menor consumo $(\mathrm{P}<0,05)$ foi observado para adição dos aditivos (Tabela 2). O consumo médio de matéria seca foi de $2,5 \%$ do peso corporal e o de fibra em detergente neutro, de $1,26 \%$ do peso corporal. Segundo Mertens (1994), o consumo de fibra em detergente neutro deveria ser próximo de 1,2\% do PC/dia para permitir suplementação adequada de concentrado e prevenir a limitação do consumo pelo enchimento do rúmen. Desse modo, a concentração de fibra nas dietas (quantitativamente principal componente nutritivo) não foi o fator limitante do consumo. Todavia, o menor consumo de nutrientes digestíveis totais das dietas com adição de própolis e monensina indica que menos energia digestível foi disponibilizada para bovinos.

A diminuição no consumo de matéria seca de dietas com monensina sódica tem sido demonstrada em diversos trabalhos como os de Vargas et al. (2001) e Oliveira et al. (2005). Segundo Nicodemo (2001), em dietas com alta proporção de grãos, os ionóforos geralmente reduzem a ingestão de alimento em cerca de $8 \%$ a $10 \%$ e melhoram a conversão alimentar, mantendo ou aumentando o ganho de peso diário dos animais. Todavia, neste experimento houve pequena redução numérica, em torno de 320 g, no consumo de matéria seca da dieta com monensina.

A adição de própolis nas dietas não influenciou o consumo de matéria seca, fato observado também em vacas (Stelzer et al., 2009) e cabras leiteiras (Lana et al., 2007) e bezerras lactentes (Casimiro, 2008). Todavia, Loureiro et al. (2007) constataram redução no consumo de matéria seca em cordeiros alimentados com rações com 15 e 30 mg de extrato de própolis/kg de peso corporal em comparação a uma ração controle.

De modo geral, os aditivos reduziram os coeficientes de digestibilidade, exceto dos carboidratos não-estruturais, que não diferiram entre as dietas ( $\mathrm{P}>0,05$, Tabela 3 ). A monensina foi o aditivo que menos reduziu a digestibilidade

Tabela 2 - Consumos médios em bovinos alimentados com dieta à base de forragem e contendo monensina ou própolis LLOS1

\begin{tabular}{|c|c|c|c|c|c|c|c|}
\hline & & \multicolumn{4}{|c|}{ Dieta } & \multirow[b]{2}{*}{$\mathrm{P}$} & \multirow[b]{2}{*}{ CV (\%) } \\
\hline & & Controle & Monensina & LLOSC1 & LLOSB3 & & \\
\hline \multirow[t]{2}{*}{ Matéria seca } & kg/dia & 6,42 & 6,10 & 6,29 & 6,28 & 0,3036 & 3,43 \\
\hline & $\%$ PC & 2,55 & 2,43 & 2,52 & 2,53 & 0,3423 & 3,72 \\
\hline \multirow[t]{2}{*}{ Matéria orgânica } & kg/dia & 5,99 & 5,68 & 5,86 & 5,85 & 0,2980 & 3,46 \\
\hline & $\% \mathrm{PC}$ & 2,37 & 2,26 & 2,35 & 2,36 & 0,3326 & 3,73 \\
\hline \multirow[t]{2}{*}{ Proteína bruta } & kg/dia & 0,93 & 0,91 & 0,92 & 0,91 & 0,4382 & 1,98 \\
\hline & $\%$ PC & 0,37 & 0,36 & 0,37 & 0,37 & 0,6081 & 2,46 \\
\hline \multirow[t]{2}{*}{ Extrato etéreo } & kg/dia & 0,17 & 0,16 & 0,17 & 0,17 & 0,3427 & 2,22 \\
\hline & $\%$ PC & 0,07 & 0,06 & 0,07 & 0,07 & 0,4252 & 2,47 \\
\hline \multirow[t]{2}{*}{ Fibra em detergente neutro } & kg/dia & 3,27 & 3,04 & 3,18 & 3,18 & 0,2456 & 4,49 \\
\hline & $\% \mathrm{PC}$ & 1,30 & 1,21 & 1,28 & 1,28 & 0,2466 & 4,64 \\
\hline \multirow[t]{2}{*}{ Fibra em detergente ácido } & kg/dia & 1,87 & 1,74 & 1,82 & 1,82 & 0,2231 & 4,09 \\
\hline & $\%$ PC & 0,74 & 0,70 & 0,73 & 0,74 & 0,2468 & 3,93 \\
\hline \multirow[t]{2}{*}{ Carboidratos totais } & kg/dia & 5,1 & 4,8 & 5,0 & 5,0 & 0,2814 & 3,58 \\
\hline & $\%$ PC & 2,0 & 1,9 & 2,0 & 2,0 & 0,2959 & 3,40 \\
\hline \multirow[t]{2}{*}{ Carboidratos não estruturais } & kg/dia & 1,86 & 1,81 & 1,83 & 1,83 & 0,4879 & 2,35 \\
\hline & $\% \mathrm{PC}$ & 0,73 & 0,72 & 0,73 & 0,74 & 0,6435 & 2,69 \\
\hline \multirow[t]{2}{*}{ Nutrientes digestíveis totais } & kg/dia & $4,24 a$ & $3,76 b$ & $3,75 b$ & $3,57 b$ & 0,0025 & 3,67 \\
\hline & $\%$ PC & $1,68 \mathrm{a}$ & $1,50 \mathrm{~b}$ & $1,50 \mathrm{~b}$ & $1,44 b$ & 0,0116 & 4,42 \\
\hline
\end{tabular}

Médias na mesma linha, seguida de letras iguais, não diferem $(\mathrm{P}<0,05)$ pelo teste Tukey.

${ }^{1}$ LLOS: produto em pó à base de extrato de própolis em duas diferentes concentrações de própolis (B e C) e dois teores alcoólicos (1 e 3): LLOSC1 e LLOSB3. 
total da matéria seca e dos componentes nutritivos. A digestibilidade total do extrato etéreo foi semelhante à da dieta controle.

Os menores coeficientes de digestibilidade total da matéria seca, da fração fibrosa e dos demais componentes nutritivos observados com o fornecimento de monensina, LLOSC1 e LLOSB3 podem estar relacionados ao espectro de ação dos produtos contendo própolis e monensina sobre a microbiota ruminal. O modo de ação da própolis parece ser diferente daquele dos ionóforos, porém não está totalmente elucidado. Takaisi-Kikuni \& Schilcher (1994) sugeriram que a atividade antibacteriana da própolis ocorre por inibição da RNA-polimerase bacteriana e, segundo Antunes et al.(1996), a ação bacteriostática e bactericida ocorreria principalmente contra bactérias gram-positivas.

Entretanto, o modo de ação dos ionóforos ocorre pela mudança no movimento de íons através das membranas de bactérias Gram-positivas, alterando o gradiente de prótons e o pH dentro da célula, o que resulta em lise da bactéria (Martin, 1998). Talvez o uso de monensina e própolis em dieta à base de forragem para bovinos em crescimento esteja selecionando e/ou diminuindo as bactérias celulolíticas (Oehem \& Pickrell, 1999), prejudicando a digestão da fração fibrosa em maior proporção na dieta e diminuindo a digestibilidade total da matéria seca, matéria orgânica, proteína bruta e dos carboidratos estruturais.

A diminuição da digestibilidade total da matéria seca causada por LLOSC1 e LLOSB3 contraria o resultado observado por Prado (2005), que avaliou os efeitos dos mesmos produtos contendo própolis sobre a digestibilidade in vitro da matéria seca de rações com $100 \%$ de volumoso e verificou aumentos de 8,3 e 25,5\% em relação às dietas com monensina e controle, respectivamente. A diferença na digestibilidade da matéria seca entre ensaios de digestibilidade in vivo e in vitro pode estar relacionada às variações inerentes a cada método.

A digestibilidade total do extrato etéreo não diferiu entre as dietas controle e monensina, seguidas de LLOSC1 e LLOSB3, que foram inferiores $(\mathrm{P}<0,05)$ e diferiram entre si. A dieta LLOSB3 teve efeito negativo mais acentuado sobre a digestibilidade total do extrato etéreo, resultados que divergem dos encontrados por Lana et al. (2007), em cabras, de digestibilidade total do extrato etéreo semelhante entre uma dieta controle e outra contendo própolis. É possível que os produtos contendo própolis (LLOS) estejam atuando não só sobre as bactérias celulolíticas, mas também sobre as lipolíticas, prejudicando a ação das lipases, o que resultou em baixa digestibilidade total do extrato etéreo.
As dietas não influenciaram $(\mathrm{P}>0,05)$ a digestibilidade dos carboidratos não-estruturais, em menor concentração na dieta. Em estudos anteriores, verificou-se que cepas bacterianas tolerantes aos produtos LLOSC1 e LLOSB3, em sua maioria, degradam carboidratos solúveis como glicose, lactose e frutose (Prado, 2008).

Houve influência dos aditivos na composição em nutrientes digestíveis totais $(\mathrm{P}<0,05)$, que foram menores para dieta monensina seguida das dietas LLOSC1 e LLOSB3. Esses resultados foram consequência da diminuição da digestibilidade dos componentes nutritivos, proteína bruta, extrato etéreo e fibra em detergente neutro, que foram influenciados pela seleção e inibição de bactérias celulolíticas e lipolíticas pela inclusão dos aditivos. O valor dos nutrientes digestíveis totais obtido com a dieta controle foi próximo ao preestabelecido para bovinos em crescimento (NRC, 2001) e a adição de monensina e própolis reduziu os teores de nutrientes digestíveis totais das rações.

É desejável que a maior parte da digestão da proteína bruta aconteça na fração intestinal, pois não há absorção de aminoácidos no rúmen e os coeficientes de digestibilidade registrados nesse compartimento são perdas de proteína na forma de amônia. Assim, os resultados da digestão ruminal e intestinal comprovaram que a dieta pode ter refletido em desbalanço entre fontes de nitrogênio e carboidratos e resultado em perdas no rúmen, principalmente de proteína, o que acarretou nos valores elevados e positivos de digestibilidade ruminal da proteína bruta (Tabela 3).

As fontes de nitrogênio de alta degradabilidade ruminal (proteína das forragens e ureia) e as fontes de lenta degradação ruminal, como os carboidratos estruturais das forragens (celulose, quantitativamente o principal nutriente) e o amido (milho), pode ter ocasionado as perdas de proteína bruta pela absorção de amônia pela parede do rúmen. Ressalta-se que o ponto máximo de produção de $\mathrm{N}-\mathrm{NH}_{3}$ foi às 2,14 h (Figura 1 ); a concentração máxima de ácidos graxos voláteis totais, às 3,9 h (Figura 2); e o $\mathrm{pH}$ foi mínimo, às $4,8 \mathrm{~h}$ (Figura 1 ). Assim, é provável que a maior disponibilidade de nitrogênio amoniacal não coincidiu com a máxima disponibilidade de energia (ATP) e esqueletos carbonados, aumentando a concentração de $\mathrm{N}-\mathrm{NH}_{3}$ no rúmen, o que resultou em absorção e não favoreceu a síntese de proteína microbiana. Todavia, mesmo nessas condições, LLOSB3 $(11,2 \%)$ e LLOSC1 $(16,3 \%)$ destacaram-se por reduzir essas perdas ruminais, que foram maiores para a dieta com monensina $(27,2 \%)$, seguido da dieta controle (24,0\%).

Ainda, a semelhança nas concentrações de amônia no rúmen e no consumo de proteína entre as dietas com aditivos e a controle (Tabela 2) e os menores valores de 
digestibilidade ruminal da proteína bruta registrados para os produtos LLOSB3 e LLOSC1 comprovam que a própolis foi mais efetiva em reduzir as perdas de $\mathrm{N}-\mathrm{NH}_{3}$ e aumentou $(\mathrm{P}<0,05)$ o fluxo de PB para os intestinos (Tabela 3 ).

A digestibilidade ruminal dos componentes da parede celular, quando expressa em porcentagem do total digerido, indicou maior fermentação $(\mathrm{P}<0,05)$ da fibra em detergente neutro e da fibra em detergente ácido da dieta com monensina, seguido de LLOSB3, LLOSC1 e da controle, que apresentaram menor valor. Entretanto, quando expressa como \% do que chega ao compartimento, os resultados acompanharam em parte aqueles obtidos para a digestibilidade total da fibra, que foi maior para dieta monensina. Entretanto, a diminuição da digestibilidade ruminal da fibra em detergente neutro observada para LLOSC1 e LLOSB3 em relação à dieta controle pode ter ocorrido não só pela seleção de bactérias como também pela provável redução na população de protozoários na presença de própolis, como observado por Ríspoli et al. (2009), que relataram que o produto LLOSC1 reduziu os protistas ciliados do rúmen de bubalinos alimentados com dieta 50:50\% (volumoso:concentrado). Também Broudiscou et al. (2000) relataram diminuição de protozoários do rúmen quando forneceram dieta com extrato de própolis em cultura contínua, uma vez que os protistas foram responsáveis por 19 a 28\% da atividade total da celulase no ambiente ruminal. Outros estudos confirmaram que a defaunação reduz a digestão de fibras (Bonhomme, 1990).

As diferenças na digestibilidade ruminal da fibra em detergente ácido $(\mathrm{P}<0,05)$ observadas para LLOSB3 em relação a LLOSC1 podem ser atribuídas à seleção das bactérias por esses produtos. Prado (2008) observou que algumas cepas de bactérias tolerantes a LLOSB3 tiveram preferência para degradar celulose, como também degradaram celobiose, xilose e arabinose, e as cepas tolerantes a LLOSC1 degradaram os mesmos polissacarídios inclusive celulose, porém mais lentamente, e nem todas as cepas tiveram capacidade celulolítica. Assim, a variação na resistência das cepas aos produtos contendo própolis

Tabela 3 - Coeficientes de digestibilidade total e parcial de dietas à base de forragem sem ou com adição de monensina e própolis LLOS3

\begin{tabular}{|c|c|c|c|c|c|c|}
\hline \multirow[b]{2}{*}{ Item } & \multicolumn{4}{|c|}{ Dieta } & \multirow[b]{2}{*}{$\mathrm{P}$} & \multirow[b]{2}{*}{ CV (\%) } \\
\hline & Controle & Monensina & LLOSC1 & LLOSB3 & & \\
\hline \multicolumn{7}{|c|}{ Digestibilidade total } \\
\hline Matéria seca (\%) & $63,2 \mathrm{a}$ & $58,7 \mathrm{~b}$ & $56,4 c$ & $54,3 d$ & 0,0001 & 1,29 \\
\hline Matéria orgânica (\%) & $64,2 \mathrm{a}$ & $59,7 b$ & $57,6 c$ & $55,0 \mathrm{~d}$ & 0,0001 & 1,32 \\
\hline Proteína bruta (\%) & $65,4 a$ & $63,1 b$ & $59,7 \mathrm{c}$ & $56,5 d$ & 0,0001 & 1,49 \\
\hline Extrato etéreo (\%) & $82,0 \mathrm{a}$ & $80,1 \mathrm{a}$ & $75,3 b$ & $65,2 c$ & 0,0001 & 2,32 \\
\hline Fibra em detergente neutro (\%) & $55,5 a$ & $49,3 b$ & $47,9 b$ & $45,5 b$ & 0,0017 & 3,89 \\
\hline Fibra em detergente ácido (\%) & $54,8 a$ & $46,1 \mathrm{~b}$ & 44,8 bc & $40,1 \mathrm{c}$ & 0,0003 & 4,22 \\
\hline Carboidratos totais (\%) & $65,0 \mathrm{a}$ & $60,2 b$ & 58,5 bc & $56,5 c$ & 0,0001 & 1,50 \\
\hline Carboidratos não estruturais (\%) & 81,7 & 79,1 & 76,9 & 75,7 & 0,1431 & 4,15 \\
\hline Nutrientes digestíveis totais & $66,1 \mathrm{a}$ & $61,9 b$ & $59,7 \mathrm{c}$ & $57,1 d$ & 0,0001 & 1,27 \\
\hline \multicolumn{7}{|c|}{ Digestibilidade ruminal } \\
\hline Matéria seca $(\%)^{1}$ & $42,9 a$ & $43,2 \mathrm{a}$ & $37,8 b$ & $39,0 b$ & 0,0004 & 2,36 \\
\hline Matéria seca $(\%)^{2}$ & $67,9 b$ & $73,7 a$ & $67,1 \mathrm{~b}$ & $71,9 a$ & 0,0003 & 1,45 \\
\hline Matéria orgânica (\%) ${ }^{1}$ & 82,1 & 86,9 & 82,9 & 88,7 & 0,0549 & 3,48 \\
\hline Proteína bruta $(\%)^{1}$ & $24,0 \mathrm{a}$ & $27,2 \mathrm{a}$ & $16,3 b$ & $11,2 \mathrm{c}$ & 0,0001 & 8,19 \\
\hline Proteína bruta $(\%)^{2}$ & $36,7 b$ & $43,0 \mathrm{a}$ & $27,3 c$ & $19,8 d$ & 0,0001 & 7,79 \\
\hline Fibra em detergente neutro $(\%)^{1}$ & $49,6 a$ & $48,5 \mathrm{ab}$ & $42,7 c$ & $43,9 \mathrm{bc}$ & 0,0078 & 4,45 \\
\hline Fibra em detergente neutro $(\%)^{2}$ & $89,5 b$ & $98,5 \mathrm{a}$ & $89,1 b$ & $96,5 \mathrm{ab}$ & 0,0097 & 3,28 \\
\hline Fibra em detergente ácido $(\%)^{2}$ & $82,1 \mathrm{c}$ & 93,8 a & $85,7 \mathrm{~b}$ & $96,3 a$ & 0,0001 & 1,49 \\
\hline Carboidratos totais $(\%)^{2}$ & $91,0 \mathrm{~b}$ & $96,8 \mathrm{ab}$ & $94,2 b$ & $102,5 \mathrm{a}$ & 0,0134 & 3,46 \\
\hline Carboidratos não estruturais $(\%)^{2}$ & $93,2 b$ & $95,2 \mathrm{ab}$ & $100,0 \mathrm{ab}$ & 108,8 a & 0,0399 & 6,07 \\
\hline \multicolumn{7}{|c|}{ Digestibilidade intestinal } \\
\hline Matéria seca $(\%)^{1}$ & $35,5 a$ & $27,2 \mathrm{c}$ & $29,8 b$ & $25,0 \mathrm{~d}$ & 0,0001 & 2,44 \\
\hline Matéria seca $(\%)^{2}$ & $32,1 \mathrm{a}$ & $26,3 b$ & $32,9 a$ & $28,1 b$ & 0,0003 & 3,41 \\
\hline Matéria orgânica $(\%)^{2}$ & 17,88 & 13,1 & 17,08 & 11,3 & 0,0549 & 19,96 \\
\hline Proteína bruta $(\%)^{1}$ & $54,5 a$ & $49,3 b$ & $51,9 \mathrm{ab}$ & $51,0 \mathrm{~b}$ & 0,0063 & 2,44 \\
\hline Proteína bruta $(\%)^{2}$ & $63,3 c$ & $56,9 d$ & $72,7 \mathrm{~b}$ & $80,2 \mathrm{a}$ & 0,0001 & 3,62 \\
\hline Fibra em detergente neutro $(\%)^{2}$ & $10,5 a$ & $1,5 b$ & $10,9 a$ & $3,5 \mathrm{ab}$ & 0,0097 & 46,21 \\
\hline Fibra em detergente ácido $(\%)^{2}$ & $17,9 \mathrm{a}$ & $6,2 \mathrm{c}$ & $14,3 \mathrm{~b}$ & $3,7 c$ & 0,0010 & 12,64 \\
\hline Carboidratos totais $(\%)^{2}$ & $8,9 a$ & $3,2 \mathrm{ab}$ & $5,7 \mathrm{a}$ & $-2,6 b$ & 0,0134 & 86,94 \\
\hline Carboidratos não estruturais $(\%)^{2}$ & $6,7 a$ & $4,7 a b$ & $-0,03 a b$ & $-8,8 b$ & 0,0399 & 938,18 \\
\hline Fluxo de PB (g/dia) ${ }^{4}$ & $705,0 \mathrm{~b}$ & $658,7 b$ & $788,0 \mathrm{a}$ & $812,5 \mathrm{a}$ & 0,0004 & 3,25 \\
\hline
\end{tabular}

Médias na mesma linha, seguida de letras iguais, não diferem $(\mathrm{P}<0,05)$ pelo teste de Tukey.

$1 \%$ do que chega ao compartimento. $2 \%$ do total digerido. ${ }^{3}$ LLOS: produto em pó à base de extrato de própolis em duas diferentes concentrações de própolis (B e C) e dois teores alcoólicos (1 e 3): LLOSC1 e LLOSB3. ${ }^{4}$ Fluxo de PB para o intestino (g/dia). 
pode ter contribuído para a maior (LLOSB3) e a menor (LLOSC1) digestibilidade ruminal da fibra em detergente ácido.

Considerando os eventos nos intestinos, a digestibilidade intestinal da PB (\% do que chega ao intestino) não diferiu entre a adição de aditivos, e somente a dieta LLOSC1 não diferiu da dieta controle. Do total da PB digerida, o maior valor de digestibilidade intestinal foi para LLOSB3, seguido do LLOSC1 e menor valor para monensina. Esses resultados indicam que os produtos LLOSC1 e LLOSB3 foram os que menos prejudicaram a digestibilidade intestinal da proteína provendo aminoácidos ao animal, como verificado pelos maiores $(\mathrm{P}<0,05)$ valores de fluxo de proteína para os intestinos (Tabela 3).

Valores negativos foram encontrados para a digestibilidade intestinal dos carboidratos não-estruturais (\% do total digerido), como reflexo da digestibilidade no rúmen (maior que 100\%), fato que não era esperado. Assim, esses valores podem ter sido ocasionados por erro de execução da técnica de coleta omasal e pela baixa quantidade de carboidratos solúveis que chegou aos intestinos (Tabela 3).

Não houve efeito da interação dieta $\times$ horário de coleta, após a alimentação, sobre o pH e as concentrações de $\mathrm{N}-\mathrm{NH}_{3}$ no rúmen de bovinos alimentados com rações à base de forragem e aditivos $(\mathrm{P}>0,05)$, porém houve efeito do horário de coleta $(\mathrm{P}<0,05)$ sobre o $\mathrm{pH}$ e o nitrogênio amoniacal (Figura 1) e efeito dos aditivos e da dieta controle $(\mathrm{P}<0,05)$ sobre o pH (Tabela 4).

$\mathrm{O}$ pH ruminal de bovinos após alimentação teve comportamento quadrático e apresentou valor mínimo de 6,04 às $4,8 \mathrm{~h}\left(\mathrm{pH}=0,029 \mathrm{H}^{2}-0,2820 \mathrm{H}+6,73824 \mathrm{R}^{2}=1,00\right.$; em que $\mathrm{H}=$ hora $)$. $\mathrm{O}$ menor valor de $\mathrm{pH}(\mathrm{P}<0,05)$ foi para LLOSB3 $(6,18)$ em relação à monensina e não diferiu da dieta controle e daquela com LLOSC1 (Tabela 4). Segundo Russell \& Dombrowski (1980), o crescimento das principais bactérias celulolíticas é comprometido em pH em torno de
6,0 a 6,1, e é totalmente inibido em valores abaixo de 5,9. Entretanto, como a dieta foi à base de forragem e dependente da atuação das bactérias celulolíticas, o pH pode não ter sido a causa do efeito negativo sobre a digestibilidade ruminal da fibra em detergente neutro (\% do que chega no rúmen) observado para as dietas com LLOSB3 e LLOSC1 em comparação à controle e com monensina, que não diferiram entre si.

O comportamento do nitrogênio amoniacal no tempo após a alimentação foi cúbico $\left(\mathrm{NH}_{3}=0,3456 \mathrm{H}^{3}-4,9566 \mathrm{H}^{2}\right.$ $+16,454 \mathrm{H}+15,774 \mathrm{R}^{2}=0,97$; em que $\mathrm{H}=$ hora) e mostrou valor máximo às 2,14 h e mínimo às 7,4 h (Figura 1 ).

$\mathrm{O}$ valor máximo de produção de $\mathrm{N}-\mathrm{NH}_{3}$ foi de $31,67 \mathrm{mg} / 100 \mathrm{~mL}$ de líquido ruminal e superior às concentrações de 19 a $23 \mathrm{mg} \mathrm{N}-\mathrm{NH}_{3} / 100 \mathrm{~mL}$ sugeridas por Mehers \& Orskov (1977) para máxima atividade fermentativa. Na concentração observada, ocorreram perdas de $\mathrm{N}-\mathrm{NH}_{3}$, que podem ser comprovadas pelos altos coeficientes de digestibilidade ruminal da proteína bruta em todas as dietas. A produção e a absorção excessiva de amônia podem aumentar a excreção de nitrogênio e o custo energético pela produção da ureia no fígado (Russell et al. 1992).

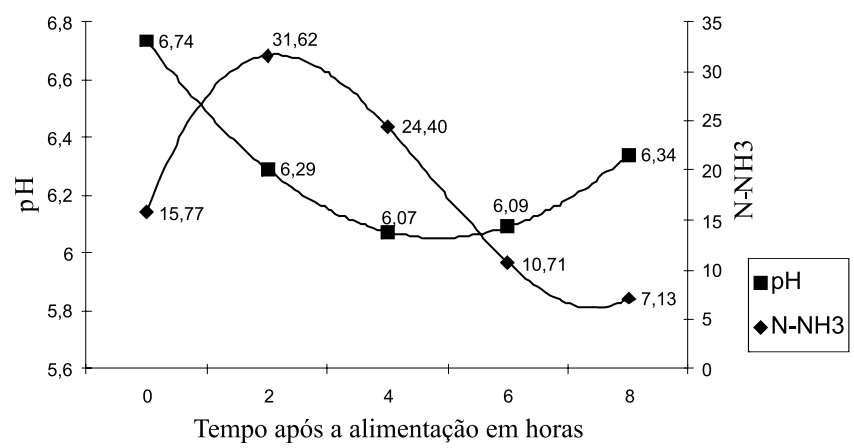

Figura 1 - pH e concentração de nitrogênio amoniacal $\left(\mathrm{N}-\mathrm{NH}_{3}\right)$ $\mathrm{mg} / 100 \mathrm{~mL}$ em bovinos alimentados com dietas contendo própolis e monensina sódica.

Tabela 4 - pH, nitrogênio amoniacal $\left(\mathrm{N}-\mathrm{NH}_{3}\right)$ e produção de ácidos graxos voláteis no rúmen de bovinos alimentados com dieta à base de forragem, sem ou com adição de monensina e própolis LLOS1

\begin{tabular}{|c|c|c|c|c|c|c|}
\hline & \multicolumn{6}{|c|}{ Dieta } \\
\hline & Controle & Monensina & LLOSC1 & LLOSB3 & $\mathrm{P}$ & $\mathrm{CV}$ \\
\hline $\mathrm{pH}$ & $6,37 \mathrm{ab}$ & $6,43 a$ & $6,24 a b$ & $6,18 b$ & 0,0145 & 4,06 \\
\hline N-NH3 (mg/100 mL) & 10,32 & 9,44 & 11,29 & 11,54 & 0,8470 & 43,95 \\
\hline AGV total $(\mu \mathrm{M} / \mathrm{mL})$ & $81,22 b$ & $80,97 b$ & $89,90 \mathrm{ab}$ & $95,04 \mathrm{a}$ & 0,0029 & 15,78 \\
\hline Acetato $(\mu \mathrm{M} / \mathrm{mL})$ & $59,03 b$ & $57,08 b$ & $64,85 a b$ & $69,28 a$ & 0,0002 & 14,84 \\
\hline Propionato $(\mu \mathrm{M} / \mathrm{mL})$ & 14,40 & 16,10 & 15,37 & 16,44 & 0,1682 & 20,80 \\
\hline Butirato $(\mu \mathrm{M} / \mathrm{mL})$ & 7,79 & 7,79 & 9,07 & 9,31 & 0,1628 & 32,93 \\
\hline Acetato:propionato & $4,23 a$ & $3,65 b$ & $4,33 a$ & $4,35 a$ & 0,0035 & 13,20 \\
\hline
\end{tabular}

Médias na mesma linha, seguida de letras iguais, não diferem $(\mathrm{P}<0,05)$ pelo teste de Tukey.

${ }^{1}$ LLOS: produto em pó à base de extrato de própolis em duas diferentes concentrações de própolis (B e C) e dois teores alcoólicos (1 e 3): LLOSC1 e LLOSB3. 
O valor mínimo de $\mathrm{N}-\mathrm{NH}_{3}$ no rúmen foi de $6,15 \mathrm{mg}$ $\mathrm{N}-\mathrm{NH}_{3} / 100$ mL e a concentraçãomédia foi de $10,64 \mathrm{NH}_{3} / 100 \mathrm{~mL}$ de líquido ruminal (Tabela 4). O menor valor ficou acima do mínimo requerido para fermentação ruminal, que é de 5,0 mg N-NH $3 / 100$ mL (Satter \& Styler, 1974) e o valor médio abaixo da concentração sugerida para que atividade de fermentação seja máxima (Mehers \& Orskov, 1977).

Não houve interação de dieta × horário de coleta, porém o horário de coleta $(\mathrm{P}<0,05)$ após a alimentação influenciou a concentração dos ácidos graxos voláteis, cujos dados em relação ao tempo foram ajustado ao modelo quadrático (Figura 2). Também foi observado efeito dos aditivos e da dieta controle $(\mathrm{P}<0,05)$ sobre as concentrações de ácidos graxos voláteis e para a razão acetato:propionato (Tabela 4).

Foi observada concentração máxima para os ácidos graxos voláteis, que variou entre 3,7 e 4,1 h após a alimentação e a menor razão acetato:propionato ficou entre 3,5 e 3,7 h após a alimentação, independentemente das dietas. O valor máximo para ácidos graxos voláteis totais foi de 94,74 mM/mL, superior ao encontrado por Lana \& Russell (2001), de 72,00 mM/mL, ao incubarem bactérias ruminais de bovinos alimentados exclusivamente com feno de gramínea por 24 horas in vitro.

A maior $(\mathrm{P}<0,05)$ concentração de acetato e de ácidos graxos voláteis totais foi verificada para LLOSB3 em relação à dieta com monensina e à controle, que não diferiram de LLOSC1. Na dieta com monensina, as concentrações de ácidos graxos voláteis totais e acetato não diferiram da controle (Tabela 4), porém apresentou a menor $(\mathrm{P}<0,05)$ razão acetato:propionato.

Contudo, separadamente, as produções de acetato e propionato diferem das observadas por Rodrigues et al. (2007), que avaliaram monensina sódica em bovinos alimentados com volumoso de baixa qualidade e observaram aumentos na concentração de propionato. Neste trabalho, a redução na razão acetato:propionato obtida para monensina foi mais influenciada pela diminuição da produção de acetato $(\mathrm{P}>0,05)$, uma vez que não houve diferença na produção de propionato entre os aditivos e a dieta controle. Segundo Newbold et al. (1995), reflexos positivos no ganho de peso de animais a pasto consumindo ionóforos poderiam estar relacionados ao aumento da energia metabolizável decorrente da redução na produção de acetato e da diminuição da metanogênese, que compensaria a perda na digestibilidade da fibra.

A dinâmica da fase líquida tem efeito sobre o crescimento microbiano e, sempre que a taxa de diluição aumenta, estimula as condições para o crescimento microbiano, o que melhora os processos de digestão até certo ponto (Van Soest, 1994). Entretanto, não foi observado efeito da interação nem das dietas $(\mathrm{P}>0,05)$ sobre as taxas de passagem de líquido, de reciclagem e de fluxo líquido, porém houve diferença $(\mathrm{P}<0,05)$ no volume ruminal entre as dietas com aditivos e a controle (Tabela 5).

Entretanto, para LLOSC1 verificou-se maior $(\mathrm{P}<0,07)$ taxa de diluição, que foi próxima àquela encontrada por Martins et al. (2006), de 9,84\%/hora para bovinos alimentados com dieta volumosa e acrescida de enzimas fibrolíticas. Por outro lado, a dieta com LLOSB3 resultou em menor taxa de diluição, cujo valor observado para a dieta com monensina (8,1\%/hora) foi inferior ao encontrado por Amaro et al. (2002), de 9,23\%/hora quando utilizaram lasalocida sódica na proporção de $200 \mathrm{mg} / \mathrm{animal} /$ dia.

Da mesma forma, a taxa de reciclagem de líquido tendeu a aumento $(\mathrm{P}<0,08)$, no caso da dieta com LLOSC1 (2,2 vezes/dia) em relação àquela com LLOSB3, que apresentou o menor valor (1,6 vez/dia). Na média, a taxa de reciclagem, no caso das dietas com os aditivos e da controle, foi de 1,9 vez/dia e próxima à relatada por Berchielli et al. (1996), de 2,0 vezes/dia.

O tempo de retenção da fase líquida é inferior a 24 horas e frequentemente menor que 12 horas (Van Soest, 1994) e, para as dietas avaliadas, foi 13 horas, sem diferença $(P>0,05)$ entre as dietas.
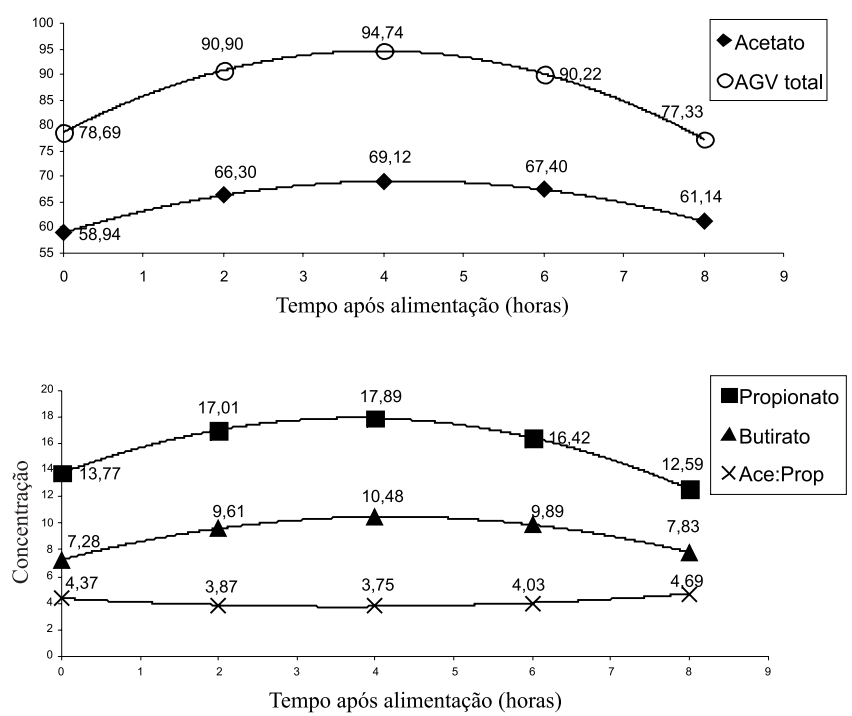

AGVt $=78,691+8,1952 \mathrm{H}-1,0457 \mathrm{H}^{2}, \mathrm{R}^{2}=0,83 ;$ Ace $=58,943+4,8141 \mathrm{H}-$ $0,5674 \mathrm{H}^{2} \mathrm{R}^{2}=0,80$; Prop $=13,765+2,2117 \mathrm{H}-0,2949 \mathrm{H}^{2}, \mathrm{R}^{2}=0,84$; But $=$ $7,2776+1,5342 \mathrm{H}-0,1831 \mathrm{H}^{2}, \mathrm{R}^{2}=0,89$; Ace:prop $=4,3679-0,347 \mathrm{H}+0,0484 \mathrm{H}^{2}$, $\mathrm{R}^{2}=0,90$.

Figura 2 - Concentrações de ácidos graxos voláteis totais, acetato, propionato, butirato $(\mu \mathrm{M} / \mathrm{mL})$ e razão acetato: propionato em bovinos com dietas contendo popólis e monensina sódica. 
Tabela 5 - Dinâmica da fase líquida de bovinos alimentados com dieta à base de forragem contendo monensina e própolis LLOS ${ }^{1}$

\begin{tabular}{|c|c|c|c|c|c|c|}
\hline & \multicolumn{6}{|c|}{ Dieta } \\
\hline & Controle & Monensina & LLOSC $^{1}$ & $\mathrm{LLOSB}^{3}$ & $\mathrm{P}$ & $\mathrm{CV}$ \\
\hline Taxa de passagem de líquido (\%/hora) & 7,5 & 8,1 & 9,4 & 6,8 & 0,0728 & 14,32 \\
\hline Tempo de retenção (horas) & 14,6 & 12,5 & 11,0 & 14,2 & 0,1487 & 15,96 \\
\hline Taxa de reciclagem (vezes/dia) & 1,8 & 1,9 & 2,2 & 1,6 & 0,0841 & 13,98 \\
\hline Taxa de fluxo de líquido (L/hora) & 4,4 & 4,8 & 5,2 & 4,2 & 0,3744 & 16,91 \\
\hline Volume ruminal (L) & $50,5 b$ & $59,5 a$ & $56,7 \mathrm{ab}$ & $62,2 \mathrm{a}$ & 0,0048 & 4,83 \\
\hline Volume ruminal (\% PV) & $20,0 \mathrm{~b}$ & $23,6 a$ & $22,6 a b$ & $25,5 a$ & 0,0046 & 5,21 \\
\hline
\end{tabular}

Médias na mesma linha, seguida de letras iguais, não diferem $(\mathrm{P}<0,05)$ pelo teste Tukey.

${ }^{1}$ LLOS: produto em pó à base de extrato de própolis em duas diferentes concentrações de própolis (B e C) e dois teores alcoólicos (1 e 3): LLOSC1 e LLOSB3.

O maior volume ruminal é verificado quando os animais são alimentados com dietas à base de forragem em relação a dietas concentradas. A redução do volume ruminal foi associada ao emprego de lasalocida sódica em bovinos (Wessels et al., 1996), no entanto, a monensina e própolis aumentaram o volume ruminal $(\mathrm{P}<0,05)$, em litros e \% do peso, em relação ao controle. $O$ aumento do volume ruminal pela inclusão de aditivos seguiu ordem de magnitude à produção de acetato e ácidos graxos voláteis totais (Tabela 4): o LLOSB3 promoveu a maior produção desses ácidos e também o maior volume ruminal, seguido pelo LLOSC1 e pela monensina sódica. Os valores registrados foram superiores aos considerados ideais por Owens \& Goestch (1988), de 15 a 21\% do PC.

\section{Conclusões}

Os produtos contendo própolis e monensina sódica têm efeitos negativos sobre os processos de digestão que refletem em menores teores de nutrientes digestíveis totais em bovinos em crescimento alimentados com dietas à base de forragem. Mais estudos são necessários para investigar os efeitos dos ionóforos e das concentrações de própolis em dietas à base de forragem, pois a monensina resulta em menor razão acetato:propionato, que reflete mais energia metabolizável para o animal e os produtos contendo própolis LLOSC1 e LLOSB3 propiciam maior fluxo de proteína para os intestinos, porém com efeitos diversos nas características ruminais.

\section{Referências}

AMARO, F.R.; LUCCI, C.S.; PEIXOTO, K.C. et al. Efeitos de níveis e períodos de adaptação à lasalocida sódica sobre os parâmetros de fermentação ruminal. Revista Brasileira de Zootecnia, v.31, n.6, p.2299-2306, 2002.

ANTUNES, R.M.P.; CATAO, R.M.R.; CEVALLOS, B.S.O. Antimicrobial activity of propolis. Revista Brasileira de Farmácia, v.77, p.15-18, 1996.

ANUÁRIO DA PECUÁRIA BRASILEIRA - ANUALPEC 2007. São Paulo: FNP Consultoria \& Comércio, 2007. 340p.
BERCHIELLI, T.T.; RODRIGUEZ, N.M.; GONÇALVES, L.C. Polietilenoglicol e cobalto-EDTA como marcadores da fase líquida ruminal. Arquivos Brasileiros de Medicina Veterinária e Zootecnia, v.48, p.463-471, 1996.

BOCK, B.J.; HARMON, D.L.; BRANDT JR., R.T. et al. Fat source and calcium level effects on finishing steer performance, digestion, and metabolism. Journal of Animal Science, v.69, p.2211-2224, 1991.

BONHOMME, A. Rumen ciliates: their metabolism and relationships with bacteria and their hosts. Animal Feed Science and Technology, v.30, p.203-266, 1990.

BROUDISCOU, L.P.; PAPON, Y.; BROUDISCOU, A.F. Effects of dry plant extracts on fermentation and methanogenesis in continuous culture of rumen microbes. Animal Feed Science and Technology, v.87, n.3-4, p.263-277, 2000.

CASIMIRO, T.R. Produtos à base de própolis para bezerras lactentes. 2008. 49f. Dissertação (Mestrado em Zootecnia) Universidade Estadual de Maringá, Maringá.

COELHO DA SILVA, J.F.; LEÃO, M.I. Fundamentos de nutrição de ruminantes. Piracicaba: Livroceres, 1979. 380p.

COLUCCI, P.E. Comparative digestion and digesta kinetics in sheep and cattle. 1984. 221f. Thesis (Ph.D. Thesis Animal Science) - University of Guelph, Guelph.

COLUCCI, P.E.; MACLEOD, G.K.; GROVUM, W.L. et al. Digesta kinetics in sheep and cattle fed diets with different forage to concentrate ratios at high and low intakes. Journal of Dairy Science, v.73, n.8, p.2143-2156, 1990.

FRANCO, S.L.; BUENO, J.H.F. Otimização de processo extrativo de própolis. Infarma, v.11, n.11/12, p. 48-51, 1999.

GOODRICH, R.D.; GARRETT, J.E.; GAST, D.R. et al. Influence of monensin on the performance of cattle. Journal of Animal Science, v.58, n.6, p.1484-1498, 1984.

ÍTAVO, C.C.B.F.; MORAIS, M.G.; COSTA, C. et al. Características de carcaça, componentes corporais e rendimento de cortes de cordeiros confinados recebendo dieta com própolis ou monensina sódica. Revista Brasileira de Zootecnia, v.38, n.5, p.898-905, 2009.

KIMURA, F.T.; MILLER, V.L. Chromic oxide measurement. Improved determination of chromic oxide in cow feed and feces. Journal of Agricultural and Food Chemistry, v.5, p.216, 1957.

LANA, R.P.; RUSSELL, J.B. Efeitos da monensina sobre a fermentação e sensibilidade de bactérias ruminais de ovinos sob dietas ricas em volumoso ou concentrado. Revista brasileira de Zootecnia, v.30, n.1, p.254-260, 2001.

LANA, R.P.; CAMARDELLI, M.M.L.; RODRIGUES, M.T. et al. Óleo de soja e própolis na alimentação de cabras leiteiras: consumo de matéria seca e de nutrientes e parâmetros de fermentação ruminal. Revista Brasileira de Zootecnia, v.36, n.1, p.191-197, 2007.

LEÃO, M.I.; VALADARES FILHO, S.C.; RENNÓ, L.N. et al. Consumos e digestibilidades totais e parciais de carboidratos totais, fibra em detergente neutro e carboidratos não-fibrosos em novilhos submetidos a três níveis de ingestão e duas 
metodologias de coleta de digestas abomasal e omasal. Revista Brasileira de Zootecnia v.34, n.2, p.670-678, 2005.

LOUREIRO, C.M.B.; SOBRINHO, A.G.S.; SANTANA, A.E. et al Eficácia do extrato de própolis no controle de helmintoses de cordeiros naturalmente infectados. In: REUNIÃO DA SOCIEDADE BRASILEIRA DE ZOOTECNIA, 44., 2007. Jaboticabal. Anais... Jaboticabal: SBZ, [2007] (CD ROM).

MAENG, W.J.; BALDWIN, R.L. Dynamics of fermentation of purified diet and microbioal growth in the rumen. Journal of Dairy Science, v.59, n.4, p.636-642, 1976.

MARTIN, S.A. Manipulation of ruminal fermentation with organic acids: a review. Journal of Animal Science, v.76, n.12, p.3123-3132, 1998.

MARTINS, A.S.; VIEIRA, P.F.; BERCHIELLI, T.T. et al. Consumo e digestibilidade aparente total em bovinos sob suplementação com enzimas fibrolíticas. Revista Brasileira de Zootecnia, v.35, n.5, p.2118-2124, 2006.

MEHERS, A.Z.; ORSKOV, E.R. A study of the artificial fiber bag technique for determining the digestibility of feeds in the rumen, Journal of Agriculture Science, v.88, p.645-650, 1977.

MERTENS, D.R. Regulation of forage intake. In: FAHEY JR., G.C. (Ed.). Forage quality, evaluation and utilization. Winsconsin: American Society of Agronomy, 1994. 998p.

NAGAJARA, T.G.; NEWBOLD, C.J.; VAN NEVEL, C.J. Manipulation of ruminal fermentation In: HOBSON, P.N.; STEWART, C.S. (Eds). The rumen microbial ecosystem. London: Blackie academic e professional, 1997. p.523-632.

NATIONAL RESEARCH COUNCIL - NRC. Nutrient requirements of dairy cattle. 7.ed. Washington, D.C.: National Academy Press, 2001. 381p.

NEWBOLD, C.J.; WALlACE, R.J.; CHEN, X.B. et al. Different strains of Saccharomyces cerevisae differ in their effects on ruminal bacterial numbers in vitro and in sheep. Journal of Animal Science, v.73, n.2, p.129-134, 1995

NICODEMO, M.L.F. Uso de aditivos na dieta de bovinos de corte. Campo Grande: Embrapa Gado de Corte, 2001. 54p. (Documentos 106).

OEHEM F.W.; PICKRELL. J. An analysis of the chronic oaral toxicity of polyether ionophore antibiotics in animals. Veterinary and Human Toxicology, v.41, p.251-257, 1999.

OLIVEIRA, M.V.M.; LANA, R.P.; JHAM, G.N. et al. Influência da monensina no consumo e na fermentação ruminal em bovinos recebendo dietas com teores baixo e alto de proteína. Revista Brasileira de Zootecnia, v.34, n.5, p.1763-1774, 2005.

OLIVEIRA, S.J.; QUEIROZ, S.A.; LANA, P.R. Efeito da monensina e da própolis sobre a atividade de fermentação de aminoácidos in vitro pelos microrganismos ruminais. Revista brasileira de Zootecnia, v.35, n.1, p.275-281, 2006.

OWENS, F.N.; GOETSCH, A.L. Ruminal fermentation. In: CHURCH, D.C. (Ed.) The ruminant animal physiology and nutrition. Englewood Cliffs: Prentice Hall, 1988. p.146-171.

PRADO, O.P.P. Produto à base de própolis na nutrição de ruminantes (LLOS). 2005. 78f. Dissertação (Mestrado em Produção Animal) - Universidade Estadual de Maringá, Maringá.

PRADO, O.P.P. Própolis e monensina sódica em dietas volumosas sobre a digestibilidade e características ruminais de bovídeos. 2008. 92f. Tese (Doutorado em Produção Animal) - Universidade Estadual de Maringá, Maringá.

REGULAMENTO (CE) N.01831/2003 DO PARLAMENTO EUROPEU E DO CONSELHO de 22 de setembro de 2003 relativo aos aditivos destinados à alimentação animal Jornal Oficial da União Européia L 268/29, 18.10.2003.
RÍSPOLI, T.B.; RODRIGUES, I.L.; MARTINS NETO, R.G. et al. Protozoários ciliados do rúmen de bovinos e bubalinos alimentados com dietas suplementadas com monensina ou própolis. Pesquisa Agropecuária Brasileira, v.44, n.1, p.92-97, 2009.

RODRIGUES, P.H.M.; PERIXOTTO JR., K.C.; MORGULLIS, S.C.F. et al. Avaliação da monensina administrada pela forma convencional ou dispositivo de liberação lenta (bólus) em bovinos alimentados com forragens de baixo valor nutritivo e suplementados ou não com uréia. Revista Brasileira de Zootecnia, v.36, n.6, p.1937-1944, 2007.

RUSSELL, J.B.; DOMBROWSKI, D.B. Effect of $\mathrm{pH}$ on the efficiency of growth by culteres of rumen bacteria in continous culture, Applied and Environmental Microbiology, v.39, p.604, 1980 .

RUSSELL, J.B.; CONNOR, J.D.; FOX, D.G. et al. A net carbohydrate and protein systems for a evaluating cattle diets. 1. Ruminal fermentation. Journal of Animal Science, v.70, p.3551-3561, 1992.

SATTER, L.D.; SLYTER, L.L. Effect of ammonia concentration on rumen microbial protein production in vitro. Britanic of Journal Nutrition, v.32, n.2, p.199-205. 1974.

SILVA, D.J.; QUEIROZ, A.C. Análises de alimentos. 3.ed. Viçosa, MG: UFV, Imprensa Universitária, 2002. 235p.

SNIFFEN, C.J.; O'CONNOR, J.D.; VAN SOEST, P.J. et al. A net carbohydrate and protein system for evaluating cattle diets: II. Carbohydrate and protein availability. Journal of Animal Science, v.70, n.12, p.3562-3577, 1992.

STATISTICAL ANALYSIS SYSTEM - SAS. SAS procedures guides. Version 9.1. Cary: SAS Institute, 2004. 176p.

STELZER, F.S.; LANA, R.P.; CAMPOS, J.M.S. et al. Desempenho de vacas leiteiras recebendo concentrado em diferentes níveis associado ou não a própolis. Revista Brasileira de Zootecnia, v.38, n.7, p.1381-1389, 2009.

STRADIOTTI JR., D.; QUEIROZ, A.C.; LANA, R.P. et al. Ação da própolis sobre a desaminação de aminoácidos e a fermentação ruminal. Revista Brasileira de Zootecnia, v.33, n.4, p.1086-1092, 2004.

TAKAISI-KIKUNI N.B.; SCHILCHER, H. Electron microscopic and microcalorimetric investigations of the possible mechanism of the antibacterial action of a defined propolis provenance. Planta Medicine, v.60, n.2, p.222-227, 1994.

UDEN, P.; COLUCCI, P.E.; VAN SOEST, P.J. Investigation of chromium, cerium and cobalt as markers in digesta. Rate of passage studies. Journal of the Science of Food and Agriculture, v.31, n.7, p.625-632, 1980.

VAN SOEST, P.J.; ROBERTSON, J.B.; LEWIS, B.A. Methods for dietary fiber, neutral detergent fiber, and nonstarch polyssacharides in relation to animal nutrition. Journal of Dairy Science, v.74, n.10, p.3583-3597, 1991.

VAN SOEST, P.J. Nutritional ecology of the ruminant. 2.ed. Ithaca: Cornell University Press, 1994. p.476.

VARGAS, L.H.; LANA, R.P.; MANCIO, A.B. et al. Influência de Rumensin, óleo de soja e níveis de concentrado sobre os consumos e os parâmetros fermentativos ruminais em bovinos. Revista Brasileira de Zootecnia, v.30, n.5 p.1650-1658, 2001.

VIEIRA, P.F. Efeito do formaldeído na proteção de proteínas e lipídeos em rações para ruminante. 1980. 98f. Tese (Doutorado em Zootecnia) - Universidade Federal de Viçosa, Viçosa, MG.

WESSELS, R.H.; TITGEMEYER, E.C.; ARMENDARIZ, C.K. et al. Lasalocid effects on ruminal degradation of protein and postruminal supply of amino acids in Holstein steers. Journal of Dairy Science, v.79, p.1802-1808, 1996. 